\title{
A STUDY TO ASSESS THE USEFULNESS OF BRAIN NATRIURETIC PEPTIDE (BNP) AND OTHER PLASMA PARAMETERS AS BIOMARKERS TO CLASSIFY ISCHAEMIC STROKE SUBTYPES, ESPECIALLY CARDIOEMBOLIC
}

\author{
Prem Singh1, Mainak Deb², Alok Verma ${ }^{3}$, Ashok Kumar Verma ${ }^{4}$, Rinkita Deb Ganguly 5 \\ ${ }_{1}^{1}$ Associate Professor and HOD, Department of Internal Medicine, GSVM Medical College, Kanpur. Uttar Pradesh. \\ 2Junior Resident, Department of Internal Medicine, GSVM Medical College, Kanpur, Uttar Pradesh. \\ ${ }^{3}$ Assistant Professor, Department of Neurology, GSVM Medical College, Kanpur, Uttar Pradesh. \\ ${ }^{4}$ Assistant Professor, Department of Radiology, GSVM Medical College, Kanpur, Uttar Pradesh. \\ ${ }_{5}^{5}$ Lecturer, Department of Biochemistry, Gurunanak Institute of Dental Sciences and Research Centre, Kolkata, Odisha.
}

ABSTRACT

\section{BACKGROUND}

Globally, stroke is a major public health problem and as per the Global Burden of Diseases (GBD) study in 1990 stroke was the second leading cause of death worldwide. Subsequent efforts to update the GBD study reported nearly 5.87 million stroke deaths globally in 2010 as compared to 4.66 million in 1990.

Objectives- To assess the usefulness of brain natriuretic peptide (BNP) and other plasma parameters as biomarkers to classify ischaemic stroke subtypes, especially cardioembolic.

\section{MATERIALS AND METHODS}

This prospective observational study was conducted in Department of Internal Medicine and Department of Neurology, LLR (Lala Lajpat Rai) Hospital and Associated Hospitals, GSVM Medical College, Kanpur (India), from October 2015 to September 2017. Random patients admitted to general ward of Medicine and Neurology Department willing to give informed consent and fulfilling requisite criterion for the study were included.

\section{RESULTS}

One hundred and eighty one patients of Acute Ischaemic Stroke had been screened during the study and finally 122 patients were included for analysis. There were 64 males $(52.5 \%)$ and 58 (45.9\%) females. The mean age of study subject was $60.73 \pm 13.36$ years with a male-to-female ratio of 1.10: 1 . The most common acute ischaemic stroke subtypes was large artery atherosclerosis $(65.5 \%)$ followed by small vessel disease $(17.2 \%)$. The mean BNP level (pcg/mL) was highest in cardioembolic subtype. The mean level of GCS was highest in small vessel disease and lowest in other aetiology. The mean level of NIHSS was highest in cardioembolic subtype and lowest in undermined aetiology group.

\section{CONCLUSION}

The present study highlighted that Atherosclerotic AIS was the most prevalent type of AIS and Mean BNP levels were highest in Cardioembolic AIS and Cardioembolic stroke had the highest mean NIHSS and lowest mean GCS (excluding "other" aetiology).

\section{KEYWORDS}

Brain Natriuretic Peptide, Stroke, Ischaemic, Cardioembolic.

HOW TO CITE THIS ARTICLE: Singh P, Deb M, Verma A, et al. A study to assess the usefulness of brain natriuretic peptide (BNP) and other plasma parameters as biomarkers to classify ischaemic stroke subtypes, especially cardioembolic. J. Evolution Med. Dent. Sci. 2018;7(10):1275-1281, DOI: 10.14260/jemds/2018/291

\section{BACKGROUND}

Globally, stroke is a major public health problem and as per the Global Burden of Diseases (GBD) study in 1990, stroke was the second leading cause of death worldwide. ${ }^{1}$ Subsequent efforts to update the GBD study reported nearly 5.87 million stroke deaths globally in 2010 as compared to 4.66 million in 1990.2,3 This indicated a 26 percent increase in global stroke deaths during the past two decades. With the rising proportion of mortality, stroke still remains the second leading cause of death worldwide. ${ }^{2,3}$

'Financial or Other Competing Interest': None.

Submission 23-01-2018, Peer Review 17-02-2018,

Acceptance 26-02-2018, Published 05-03-2018.

Corresponding Author:

Dr. Prem Singh,

Associate Professor and HOD,

Department of Internal Medicine,

GSVM Medical College,

Kanpur, India.

E-mail: drpremsingh22gsvm@gmail.com

DOI: $10.14260 /$ jemds $/ 2018 / 291$

\section{(c) () $($ )}

India has been experiencing significant demographic, economic and epidemiological transition during the past two decades. These have resulted in an increase in life expectancy and consequently an increase in ageing population. ${ }^{4}$ Reliable morbidity and mortality estimates for stroke in India are very limited.5-9

There are two main types of stroke, ischaemic and haemorrhagic. In ischaemic stroke, blood supply to the part of brain is reduced and it causes dysfunction of the brain tissue in that area. The main causes of cerebral infarction are Thrombosis (obstruction of a blood vessel by a blood clot forming locally), Embolism (obstruction due to an embolus from elsewhere in the body), Systemic hypoperfusion and Cerebral venous sinus thrombosis. ${ }^{10}$

In thrombotic stroke, a thrombus (originates from large vessel and small vessel), usually forms around atherosclerotic plaques. In embolic stroke emboli most commonly arise from the heart (mainly in atrial fibrillation), but may also originate from elsewhere in arterial tree.11

Brain natriuretic peptide (BNP) is a 32-amino-acid cardiac natriuretic peptide neurohormone with a 17-amino- 
acid ring structure and the proteolytic enzymes corin and furin split the prohormone into its two equimolar subsections of the active BNP-32 (amino acid 77-108) and the remaining part of the prohormone, biologically inactive NT-pro BNP (amino acid 1-76) which can also be measured by immunoassay.12 Brain natriuretic peptide (BNP) is synthesised by cardiomyocytes in a short time and in large quantities and released after the stimulation of cardiomyocytes in response to volume or pressure overload. ${ }^{12}$

It is also known that BNP is secreted in the brain, primarily the hypothalamus and this release is induced by cerebral ischaemia. ${ }^{13-15}$

Many studies have demonstrated a relationship between elevated levels of brain natriuretic peptide and the acute phase of ischaemic stroke (AIS). ${ }^{16-18}$

Patients with elevated BNP or NT-proBNP levels around the time of their incident stroke are more likely to have a cardioembolic mechanism identified ${ }^{19}$ to have a worse outcome from their stroke and to have an increased risk of future events such as recurrent ischaemic stroke and death. ${ }^{20}$

The present study was done to assess the usefulness of brain natriuretic peptide (BNP) and other plasma parameters as biomarkers to classify ischaemic stroke subtypes, especially cardioembolic.

\section{MATERIALS AND METHODS}

This prospective, observational study was conducted in Department of Internal Medicine and Department of Neurology, LLR (Lala Lajpat Rai) Hospital and Associated Hospitals, GSVM Medical College, Kanpur (India) from October 2015 to September 2017. Random patients admitted to general ward of Medicine and Neurology Department willing to give informed consent and fulfilling requisite criterion for the study were included.

A total of 181 patients of acute ischaemic stroke had been screened during the study and finally 122 patients were included for analysis.

\section{Inclusion Criteria}

- $\quad$ Age 25 - 80 years.

- Clinical features suggestive of CVA diagnosed with Acute Ischaemic Stroke.

\section{Exclusion Criteria}

- $\quad$ Renal disease with CKD grade $>2$.

- Heart failure with NYHA class $>1$ or chronic cor pulmonale.

- Those who were thrombolysed.

- History of heart surgery ever.

- Atrial Fibrillation/ Flutter documented at an earlier date ever.

- Presentation to our Hospital more than 72 hours after stroke onset.

- Patients on Nesiritide therapy.

- $\quad$ Expired before completing OR did not complete all investigations required in the study.

\section{Methodology}

Detailed history was taken about age, sex, chief complaints along with onset, duration and progress of symptoms, past history, treatment history and personal history with special emphasis on cardiovascular risk factors. Thorough physical examination followed in the Emergency ward with special emphasis on neurological system; presenting Glasgow Coma Scale (GCS) score was recorded. ${ }^{21}$ The National Institutes of Health Stroke Scale or NIH Stroke Scale (NIHSS) were recorded within 3 hours of admission. 22

Blood sample for BNP measurement were taken from all subjects in the emergency room immediately after admission in chilled EDTA tubes and before treatment started. BNP was measured within 24 hours of admission using Alere Triage Meter-Pro 55070 immunoassay machine that was regularly calibrated and maintained by qualified technicians. Fasting Lipid Profile and Liver Function Tests were sent within 24 hours of admission.

Neuroimaging (Computerised Tomographic Scan of Brain) were done to confirm diagnosis of stroke within 24 hours of admission. All patients with intracranial bleed were excluded. In those patients with isolated middle cerebral artery territory AIS, ASPECTS (Alberta Stroke Program Early CT Score) ${ }^{19}$ was determined, supplemented by DWi-ASPECTS (similar score determined from a Magnetic Resonance Imaging of the Brain) in some cases; DWi ASPECTS was preferred wherever available. ${ }^{23}$ The score divides the MCA territory into 10 regions of interest and represents the number of regions with no evidence of involvement in the scan.

Transthoracic Echocardiography and Doppler Study of Carotid and Vertebral vessels were performed within first 3 days of admission.

\section{Sub-Classification of AIS}

Ischaemic Stroke subtypes were classified according to the TOAST (Trial of Org 10172 in Acute Stroke Treatment) classification widely used in recent literature.24 TOAST classification system includes five categories-

1. A: Large-artery Atherosclerosis,

2. S: Small-artery occlusion (lacunar),

3. C: Cardioembolism,

4. U: Stroke of Undetermined aetiology,

5. O: Stroke of Other determined aetiology.

\section{Statistical Analysis}

Results were tabulated in Microsoft Office Excel 2007 worksheet and expressed in mean \pm standard deviation for continuously distributed variables and in absolute numbers and percentages for discrete variables. Appropriate standard statistical methods were utilised. ANOVA and Pearson's two tailed correlation coefficient was used and p-value was computed; $p$ value of less than 0.05 was considered significant unless otherwise specified. SPSS version 19 was used for statistical analysis. The results were graphically represented using Microsoft Office Excel 2007.

\section{RESULTS}

A total of 122 patients were enrolled in the present study for final analysis. The percentage of male and female patients were $52.5 \%$ and $45.9 \%$ respectively. The male-to-female ratio was 1.10: 1 . The mean age of the study population was $60.73 \pm 13.36$ years. In present study, there were 80 patients in the Atherosclerotic subtype constituting the maximum number of patients $(65.5 \%)$ followed by small vessel disease $(17.2 \%)$, cardioembolic (12.3\%), undetermined aetiology 
(4.91\%) and dissection of artery (0.8\%). The mean age in atherosclerotic subtype, small vessel disease, cardioembolic, undetermined aetiology and dissection of artery were $64.3 \pm$ $10.68,60.62 \pm 14.32,53.53 \pm 13.1,37.17 \pm 5.46$ and 30 years respectively. The mean serum cholesterol levels $(\mathrm{mg} / \mathrm{dL})$, in atherosclerotic subtype, small vessel disease, cardioembolic, undetermined aetiology and dissection of artery were 189.18 $\pm 49.89,186.43 \pm 41.03,175.8 \pm 44.62,148.17 \pm 31.23$ and 168 respectively. The mean Serum Triglyceride $(\mathrm{mg} / \mathrm{dL})$ in atherosclerotic subtype, small vessel disease, cardioembolic, undetermined aetiology and dissection of artery were 129.91 $\pm 49.81133 .93 \pm 48.98,129.53 \pm 75.39,100.63 \pm 45.19$ and 89.9 respectively. The mean Serum HDL $(\mathrm{mg} / \mathrm{dl})$ in atherosclerotic subtype, small vessel disease, cardioembolic, undetermined aetiology and dissection of artery were $49 \pm$ 7.56, $46.36 \pm 7.77,52.19 \pm 8.33,46.98 \pm 8.97$ and 61.1 respectively. The mean Serum LDL $(\mathrm{mg} / \mathrm{dL})$ in atherosclerotic subtype, small vessel disease, cardioembolic, undetermined aetiology and dissection of artery were 106.74 $\pm 39.90,107 \pm 39.51,92.93 \pm 41.53,78.70 \pm 23.74$ and 79 respectively. The mean, HbA1c \% in atherosclerotic subtype, small vessel disease, cardioembolic, undetermined aetiology and dissection of artery were $6.52 \pm 2.10,6.72 \pm 1.92,5.58 \pm$ $0.64,5.30 \pm 0.33$ and 5.50 respectively. The mean BNP level $(\mathrm{pcg} / \mathrm{mL})$ in atherosclerotic subtype, small vessel disease, cardioembolic, undetermined aetiology and dissection of artery were $515.22 \pm 330.90,247.51 \pm 39.21,801.30 \pm 381$, $358.82 \pm 144.32$ and 467 respectively. The other details are given in Table Number 1.

The mean level of GCS in atherosclerotic subtype, small vessel disease, cardioembolic, undetermined aetiology and dissection of artery were $11.44 \pm 2.90,14.05 \pm 1.36,10.93 \pm$ $2.71,13.33 \pm 2.66$ and 10 respectively. The mean level of NIHSS in atherosclerotic subtype, small vessel disease, cardioembolic, undetermined aetiology and dissection of artery were $12.77 \pm 9.92,4.10 \pm 2.93,13.93 \pm 10.87,4.33 \pm$ 4.54 and 8 respectively. The other details are given in table number 2. The statistical analyses of BNP with other parameters are given in Table Number 3.

Aspect Score was calculated in a subgroup of 85 patients with isolated Middle Cerebral Artery Territory AIS and subgroup analysis was done. BNP levels showed no correlation with ASPECTS (-0.085). ASPECTS also did not show significant correlation with GCS $(+0.150)$ and NIHSS $(+0.041)$. GCS levels showed very strong negative correlation with NIHSS -0.829 . The detailed statistical analysis is given in Table Number 4.

\begin{tabular}{|c|c|c|c|c|c|c|}
\hline & Investigations & $\begin{array}{c}\text { Atherosclerotic } \\
\text { (N=80) }\end{array}$ & $\begin{array}{c}\text { Small Vessel } \\
\text { Disease } \\
(\mathrm{N}=21)\end{array}$ & $\begin{array}{l}\text { Cardioembolic } \\
\qquad(\mathrm{N}=15)\end{array}$ & $\begin{array}{c}\text { Undetermined } \\
\text { Aetiology } \\
(\mathrm{N}=6)\end{array}$ & $\begin{array}{l}\text { Other Aetiology } \\
\qquad(\mathrm{N}=01)\end{array}$ \\
\hline 1 & Haemoglobin & $11.33 \pm 1.72$ & $11.77 \pm 1.79$ & $11.81 \pm 2.09$ & $11.05 \pm 3.33$ & 10.30 \\
\hline 2 & $\begin{array}{c}\text { Total Leucocyte } \\
\text { Count }\end{array}$ & $12547 \pm 3696$ & $10748 \pm 3131$ & $12433 \pm 3854$ & $15733 \pm 1644$ & 10000 \\
\hline 3 & $\begin{array}{l}\text { Serum Bilirubin } \\
(\mathrm{mg} / \mathrm{dL})\end{array}$ & $0.94 \pm 0.42$ & $0.83 \pm 0.26$ & $1.12 \pm 0.46$ & $0.95 \pm 0.33$ & 1.10 \\
\hline 4 & $\begin{array}{c}\text { Serum AST/SGOT } \\
\text { (IU/dL) }\end{array}$ & $34.24 \pm 16.23$ & $35.71 \pm 12.93$ & $50.53 \pm 37.17$ & $64.50 \pm 37.20$ & 29 \\
\hline 5 & $\begin{array}{c}\text { Serum ALT/SGPT } \\
(\mathrm{IU} / \mathrm{dL})\end{array}$ & $29.16 \pm 12.29$ & $31.38 \pm 15.26$ & $51.93 \pm 40.43$ & $60.17 \pm 40.15$ & 15 \\
\hline 6 & $\begin{array}{l}\text { Serum Albumin } \\
(\mathrm{mEq} / \mathrm{dL})\end{array}$ & $4.16 \pm 0.52$ & $4.33 \pm 0.46$ & $4.19 \pm 0.44$ & $4.28 \pm 0.71$ & 4.20 \\
\hline 7 & $\begin{array}{l}\text { Serum Creatinine } \\
(\mathrm{mg} / \mathrm{dL})\end{array}$ & $0.99 \pm 0.02$ & $0.92 \pm 0.14$ & $1.01 \pm 0.16$ & $0.93 \pm 0.08$ & 0.90 \\
\hline 8 & $\begin{array}{c}\text { Serum Cholesterol } \\
(\mathrm{mg} / \mathrm{dL})\end{array}$ & $189.18 \pm 49.89$ & $186.43 \pm 41.03$ & $175.8 \pm 44.62$ & $148.17 \pm 31.23$ & 168 \\
\hline 9 & $\begin{array}{c}\text { Serum Triglyceride } \\
(\mathrm{mg} / \mathrm{dL})\end{array}$ & $129.91 \pm 49.81$ & $133.93 \pm 48.98$ & $129.53 \pm 75.39$ & $100.63 \pm 45.19$ & 89.9 \\
\hline 10 & $\begin{array}{c}\text { Serum HDL } \\
(\mathrm{mg} / \mathrm{dL})\end{array}$ & $49 \pm 7.56$ & $46.36 \pm 7.77$ & $52.19 \pm 8.33$ & $46.98 \pm 8.97$ & 61.1 \\
\hline 11 & Serum LDL $(\mathrm{mg} / \mathrm{dL})$ & $106.74 \pm 39.90$ & $107 \pm 39.51$ & $92.93 \pm 41.53$ & $78.70 \pm 23.74$ & 79 \\
\hline 12 & Serum BNP & $515.22 \pm 330.90$ & $247.51 \pm 39.21$ & $801.30 \pm 381$ & $358.82 \pm 144.32$ & 467 \\
\hline \multicolumn{7}{|c|}{ Table 1} \\
\hline
\end{tabular}

\begin{tabular}{|c|c|c|c|c|}
\hline Mean Levels & Mean GCS & Mean NIHSS & Heart Rate (from ECG) & Mean Arterial Pressure (MAP) \\
\hline A: Atherosclerotic & $11.44 \pm 2.90$ & $12.77 \pm 9.92$ & $77.04 \pm 14.89$ & $90.37 \pm 8.63$ \\
\hline S: Small vessel disease & $14.05 \pm 1.36$ & $4.10 \pm 2.93$ & $78.48 \pm 12.72$ & $97.14 \pm 9.07$ \\
\hline C: Cardioembolic & $10.93 \pm 2.71$ & $13.93 \pm 10.87$ & $77.13 \pm 14.81$ & $80.33 \pm 5.69$ \\
\hline U: Undetermined Aetiology & $13.33 \pm 2.66$ & $4.33 \pm 4.54$ & $77.00 \pm 14.95$ & $85.67 \pm 3.27$ \\
\hline 0: Other Aetiology & $10.0 \pm 0.0$ & $8.0 \pm 0.0$ & $64.00 \pm 0.00$ & $84.00 \pm 0.00$ \\
\hline \multicolumn{5}{|c|}{ Table 2 } \\
\hline
\end{tabular}




\begin{tabular}{|c|c|c|}
\hline Variable Name & Pearson's Correlation Coefficient to BNP Level & Significance Level (Two Tailed) \\
\hline Age & -0.073 & $<0.05$ \\
\hline S. HDL & +0.102 & $<0.05$ \\
\hline S. LDL & +0.180 & $<0.05$ \\
\hline S. Cholesterol & +0.177 & $<0.05$ \\
\hline S. Triglyceride & +0.163 & $<0.05$ \\
\hline HbA1c \% & -0.004 & $<0.05$ \\
\hline Haemoglobin & +0.086 & $<0.05$ \\
\hline Total Leucocyte Count (TLC) & -0.180 & $<0.01$ \\
\hline S. Creatinine & $\mathbf{+ 0 . 2 5 9}$ & $<0.05$ \\
\hline S. SGPT & +0.063 & $<0.05$ \\
\hline S. SGOT & +0.098 & $<0.05$ \\
\hline S. Bilirubin & $\mathbf{+ 0 . 2 0 2}$ & $<0.05$ \\
\hline S. Albumin & -0.111 & $<0.05$ \\
\hline S. Sodium & -0.123 & $<0.05$ \\
\hline S. Potassium & -0.057 & $<0.05$ \\
\hline S. Calcium & -0.026 & $<0.05$ \\
\hline Heart Rate & -0.189 & $<0.05$ \\
\hline GCS & +0.215 & $<0.01$ \\
\hline NIHSS & -0.625 & $<0.01$ \\
\hline \multicolumn{2}{|l|}{ Table 3. Statistical Analysis of Correlation of BNP with Other Parameters } \\
\hline
\end{tabular}

\begin{tabular}{|c|c|c|c|c|c|}
\hline & & BNP Level & Glasgow Coma Scale & NIHS Score & Score Aspect \\
\hline \multirow{3}{*}{ BNP Level } & Pearson Correlation & 1 & $-.812^{* *}$ & $-.727^{* *}$ & -.633 \\
\hline & Sig. (2-tailed) & & 0.00 & 0.00 & 0.00 \\
\hline & $\mathrm{N}$ & 85 & 85 & 85 & 85 \\
\hline \multirow{3}{*}{$\begin{array}{c}\text { Glasgow Coma } \\
\text { Scale }\end{array}$} & Pearson Correlation & $-.812^{* *}$ & 1 & $-.778^{* *}$ & 0.150 \\
\hline & Sig. (2-tailed) & 0.001 & & 0.001 & .098 \\
\hline & $\mathrm{N}$ & 85 & 85 & 85 & 85 \\
\hline \multirow{3}{*}{ NIHS score } & Pearson Correlation & $0.727^{* *}$ & $-.778^{* *}$ & 1 & 0.659 \\
\hline & Sig. (2-tailed) & 0.00 & 0.00 & & 0.00 \\
\hline & $\mathrm{N}$ & 85 & 85 & 85 & 85 \\
\hline \multirow{3}{*}{ Score ASPECT } & Pearson Correlation & -.633 & .676 & .659 & 1 \\
\hline & Sig. (2-tailed) & 0.00 & 0.00 & 0.00 & \\
\hline & $\mathrm{N}$ & 85 & 85 & 85 & 85 \\
\hline \multicolumn{6}{|c|}{${ }^{* *}$ Correlation is Significant at the 0.01 Level (2-Tailed) } \\
\hline
\end{tabular}

\section{DISCUSSION}

Stroke is an acute and rapidly progressive neurological disorder and constituting about $50 \%$ of neurological emergencies and responsible for significant morbidity also. ${ }^{25}$

Various imaging methods play an important role in the immediate diagnosis of stroke and the determination of stroke subtypes, but they might also become significant after a delay. ${ }^{26}$ The time restrictions associated with imaging have led researchers to consider other possible methods of rapid diagnosis such as using biomarkers.

Brain natriuretic peptide (BNP) is a neurohormone and which is produced in response to such cardiovascular alterations from ventricular myocytes (due to stretching from pressure or volume overload), and atrial myocytes ${ }^{27-30}$ cardioembolic stroke and post-stroke mortality ${ }^{17,31-34}$ have been proved in many studies. ${ }^{32,35}$

In present study, there were 80 patients in the large artery atherosclerotic subtype constituting the maximum number of patients (65.5\%) followed by small vessel disease (17.2\%), cardioembolic (12.3\%), undetermined aetiology (4.91\%) and dissection of artery (0.8\%).

Some authors in their studies highlighted that most common aetiology of stroke subtypes was cardioembolic, 36,3740,41 while some other authors have been reported large artery type as most common stroke subtype. $42,43,44$
In present study, mean of Mean Arterial Blood Pressure (MAP) was highest in the Small Vessel AIS subtype (97.14 \pm $9.07 \mathrm{mmHg}$ ) followed by Atherosclerotic Subtype (90.37 \pm $8.63 \mathrm{mmHg}$ ) and lowest in Cardioembolic AIS (80.33 $14 \pm$ $5.69 \mathrm{mmHg}$ ). In the studies of Estrada et al and Eguchi et al, it was found that BNP levels increased in the acute phase of stroke and that there was a positive correlation between blood pressure levels and BNP levels.

In present study, the mean BNP level $(\mathrm{pcg} / \mathrm{mL})$ measurements was highest among cardioembolic AIS types and our results were found similar to others studies. ${ }^{45,37,38,39,41,46,44}$ In present study, next highest values were for Atherosclerotic subgroup (515.22 $\pm 330.90 \mathrm{pg} / \mathrm{mL})$, presumably due to large volumes of infarction. ${ }^{21}$ Small vessel disease had a low mean BNP level $(247.51 \pm 39.21 \mathrm{pg} / \mathrm{mL})$ again presumably related to the small volume of infarcted tissue.

Extensive search of literature revealed that various authors have been finalised cut-off value of BNP as 55.5 $\mathrm{pg} / \mathrm{mL}, 76 \mathrm{pg} / \mathrm{mL}, 77 \mathrm{pg} / \mathrm{mL}, 90 \mathrm{pg} / \mathrm{mL}, 140 \mathrm{pg} / \mathrm{mL}, 265$ $\mathrm{pg} / \mathrm{mL}, 342 \mathrm{pg} / \mathrm{mL}$ and $360 \mathrm{pg} / \mathrm{mL}$ in order to determine cardioembolic nature of AIS. ${ }^{47-53}$ In present study, we have not determined cut-off value of BNP in between cardioembolic stroke and other stroke subtypes. 
The present study showed weak positive correlation of serum total bilirubin levels with BNP level (Pearson's 2-tailed correlation coefficient $+0.202 ; \mathrm{p}<0.05)$ and serum SGPT $(+0.098, \mathrm{p}<0.05)$ and serum SGPT $(+0.063, \mathrm{p}<0.05)$ were also weakly correlated to BNP level. Serum albumin showed a weak negative correlation (Pearson's 2-tailed correlation coefficient $-0.111, \mathrm{p}<0.05$ ) with BNP level. The lower values of serum albumin and higher values of serum total bilirubin were similar to those reported by Cojocaru. 48

In present study, Mean Glasgow Coma Scale scores were highest in Small Vessel Disease AIS (14.05 \pm 1.36), likely due to their small infarct core size and subcortical nature and this was followed by AIS of undetermined aetiology (13.33 \pm $2.66)$, and large artery atherosclerotic (11.44 \pm 2.90$)$ and cardioembolic $(10.93 \pm 2.71)$ and other determined aetiology $(10.0 \pm 0.00)$. GCS was found to have a strong negative correlation with BNP values (Pearson's 2-tailed correlation coefficient $-0.625 ; \mathrm{p}<0.01$ ). Our results are found to be similar to the other studies by Cakir $\mathrm{Z}$ et al ${ }^{25}$ and Makikallio et al. ${ }^{20}$

In present study, mean NIHS score was the highest in Cardioembolic subtype as well $(13.93 \pm 10.87)$ reflecting their clinically severe nature followed by atherosclerotic AIS $(12.77 \pm 9.92)$, possibly due to large infarct size. NIHS score was found to be strongly correlated to BNP levels (Pearson's 2 -tailed correlation coefficient +0.659 ; $\mathrm{p}<0.01$ ). Several other studies also have shown a significant correlation between plasma BNP levels and NIHS score. $21,26,27,28,29$

In present study, we also have done correlations between ASPECT score, GCS, NIHSS score and also BNP level. Subgroup analysis revealed that ASPECT score was strongly positively correlated with GCS AND ASPECT score was strongly negatively correlated to NIHSS score and ASPECT score was not significantly correlated with BNP level.

\section{CONCLUSION}

In present study, Atherosclerotic AIS was the most prevalent type of AIS followed by Small Vessel Disease AIS and was slightly more common in males. Mean BNP levels were highest in Cardioembolic AIS and Cardioembolic stroke had the highest mean NIHSS and lowest mean GCS (excluding "other" aetiology).

The data suggests that BNP levels can help to point out cardioembolic origin of an embolus whose workup would take time or whose workup suggested cryptogenic origin. Their incorporation into AIS management protocol might help to identify candidates who will do better with immediate anticoagulation rather than performing invasive TEE or continual Holter monitoring waiting weeks to months to detect an episode of evanescent $\mathrm{AF}$, while sustaining excess risk by being on the suboptimal antiplatelet therapy.

\section{REFERENCES}

[1] Murray CJL, Lopez AD. Global health statistics: a compendium of incidence, prevalence and mortality estimates for over 200 conditions. Cambridge, MA: Harvard University Press 1996.

[2] Strong K, Mathers C, Bonita R. Preventing stroke: saving lives around the world. Lancet Neurol 2007;6(2):182-7.
[3] Strong K, Mathers C. The global burden of stroke. In: Mohr JP, Grotta JC, Wolf PA, eds. Stroke: pathophysiology, diagnosis and management. $5^{\text {th }}$ edn. Philadelphia, PA: Elsevier 2011: p. 279-89.

[4] Dalal P, Bhattacharjee M, Vairale J, et al. UN millennium development goals: Can we halt the stroke epidemic in India? Ann Indian Acad Neurol 2007;10(3):130-6.

[5] Kamalakannan SK, Gudlavalleti ASV, Murthy Gudlavalleti VS, et al. Challenges in understanding the epidemiology of acquired brain injury in India. Ann Indian Acad Neurol 2015;18(1):66-70.

[6] Taylor FC, Sureshkumar K. Stroke in India Factsheet. https://www.researchgate.net/publication/2641166 05 Stroke_in_India_-_Fact-sheet_Updated_2012, accessed on July 23, 2017.

[7] Gourie-Devi M. Epidemiology of neurological disorders in India: review of background, prevalence and incidence of epilepsy, stroke, Parkinson's disease and tremors. Neurol India 2014;62(6):588-98.

[8] Dalal PM. Burden of stroke: Indian perspective. Int J Stroke 2006;1(3):164-6.

[9] Dalal PM, Bhattacharjee M. Stroke epidemic in India: hypertension-stroke control programme is urgently needed. J Assoc Physicians India 2007;55:689-91.

[10] Donnan GA, Fisher M, Macleod M, et al. Stroke. Lancet 2008;371(9624):1612-23.

[11] Stam J. Thrombosis of the cerebral veins and sinuses. The New England Journal of Medicine 2005;352(17):1791-8.

[12] Azzazy HM, Christenson RH. B-type natriuretic peptide: physiologic role and assay characteristics. Heart Fail Rev 2003;8(4):315-20.

[13] Takahashi K, Totsune K, Sone M, et al. Human brain natriuretic peptide-like immunoreactivity in human brain. Peptides 1992;13(1):121-3.

[14] Nogami M, Shiga J, Takatsu A, et al. Immunohistochemistry of atrial natriuretic peptide in brain infarction. Histochem J 2001;33(2):87-90.

[15] Giuffrida R, Bellomo M, Polizzi G, et al. Ischemiainduced changes in the immunoreactivity for endothelin and other vasoactive peptides in the brain of the Mongolian gerbil. J Cardiovasc Pharmacol 1992;20 Suppl 12:S41-S4.

[16] Shibazaki K, Kimura K, Okada Y, et al. Plasma brain natriuretic peptide as an independent predictor of inhospital mortality after acute ischemic stroke. Intern Med 2009;48(18):1601-6.

[17] Jensen JK, Atar D, Kristensen SR, et al. Usefulness of natriuretic peptide testing for long-term risk assessment following acute ischemic stroke. Am J Cardiol 2009;104(2):287-91.

[18] Di Angelantonio E, De Castro S, Toni D, et al. Determinants of plasma levels of brain natriuretic peptide after acute ischemic stroke or TIA. J Neurol Sci 2007;260(1-2):139-42.

[19] Rodríguez-Yáñez M, Sobrino T, Blanco M, et al. High serum levels of pro-brain natriuretic peptide (pro BNP) identify cardioembolic origin in undetermined stroke. Disease Markers 2009;26(4):189-95. 
[20] Makikallio AM, Makkikallio TH, Korpelainen JT, et al. Brain natriuretic peptides and mortality after stroke. Stroke 2005;36(5):1016-20.

[21] Teasdale G, Jennett B. Assessment of coma and impaired consciousness. A practical scale. Lancet 1974;2(7872):81-4.

[22] National Institute of Health, National Institute of Neurological Disorders and Stroke. Stroke Scale. http://www.ninds.nih.gov/doctors/NIH-StrokeScale.pdf

[23] Pexman JH, Barber PA, Hill MD, et al. Use of the Alberta Stroke Program Early CT Score (ASPECTS) for assessing CT scans in patients with acute stroke. Am J Neuroradiol 2001;22(8):1534-42.

[24] Adams HP, Davis PH, Leira EC, et al. Baseline NIH Stroke Scale score strongly predicts outcome after stroke: a report of the Trial of Org 10172 in Acute Stroke Treatment (TOAST). Neurology 1999;53(1):126-31.

[25] Waxman SG. Correlative neuroanatomy. 24th edn. New Haven: Lange Medical Books 1999: p. 68-172.

[26] Schwamm LH, Audebert HJ, Amarenco P, et al. Recommendations for the implementation of telemedicine within stroke systems of care: a policy statement from the American Heart Association. Stroke 2009;40(7):2635-60.

[27] Goetze JP, Friis-Hansen L, Rehfeld JF, et al. Atrial secretion of B-type natriuretic peptide. European Heart Journal 2006;27(14):1648-50.

[28] Gould PA, Gula LJ, Bhayana V, et al. Characterization of cardiac brain natriuretic peptide release in patients with paroxysmal atrial fibrillation undergoing left atrial ablation. Circ Arrhythm Electrophysiol 2010;3:18-23.

[29] Shimizu H, Murakami Y, Inoue S, et al. High plasma brain natriuretic polypeptide level as a marker of risk for thromboembolism in patients with non-valvular atrial fibrillation. Stroke 2002;33(4):1005-10.

[30] Inoue S, Murakami Y, Sano K, et al. Atrium as a source of brain natriuretic polypeptide in patients with atrial fibrillation. J Card Failure 2000:6(2):92-6.

[31] Maruyama K, Uchiyama S, Shiga T, et al. Brain natriuretic peptide is a powerful predictor of outcome in stroke patients with atrial fibrillation. Cerebrovasc Dis Extra 2017;7(1):35-43.

[32] Nigro N, Wildi K, Mueller C, et al. BNP but Not s-c Tnln is associated with cardioembolic aetiology and predicts short and long term prognosis after cerebrovascular events. PLoS One 2014;9(7):e102704.

[33] Bower JK, Lazo M, Matsushita K, et al. N-Terminal ProBrain Natriuretic Peptide (NT-proBNP) and risk of hypertension in the Atherosclerosis Risk in Communities (ARIC) Study. American Journal of Hypertension 2015;28(10):1262-6.

[34] Greisenegger S, Segal HC, Burgess AI, et al. Biomarkers and mortality after transient ischemic attack and minor ischemic stroke: population-based study. Stroke 2015;46(3):659-66.

[35] Longstreth WT, Kronmal RA, Thompson JL, et al. Amino terminal pro-b-type natriuretic peptide, secondary stroke prevention and choice of antithrombotic therapy. Stroke 2013;44(3):714-9.
[36] Grau AJ, Weimer C, Buggle F, et al. Risk factors, outcome and treatment in subtypes of ischemic stroke: the German stroke data bank. Stroke 2001;32(11):2559-66.

[37] Fonseca AC, Matias JS, e Melo PT, et al. N-terminal probrain natriuretic peptide as a biomarker of cardioembolic stroke. International Journal of Stroke 2011;6(5):398-403.

[38] Rost NS, Biffi A, Cloonan L, et al. Brain natriuretic peptide predicts functional outcome in ischemic stroke. Stroke 2012;43(2):441-5.

[39] Hajsadeghi S, Amin KL, Bakhshandeh $\mathrm{H}$, et al. The diagnostic value of $n$-terminal pro-brain natriuretic peptide in differentiating cardioembolic ischemic stroke. Journal of Stroke and Cerebrovascular Diseases 2013;22(4):554-60.

[40] Tomita H, Metoki N, Saitoh G, et al. Elevated plasma brain natriuretic peptide levels independent of heart disease in acute ischemic stroke: correlation with stroke severity. Hypertens Res 2008;31(9):1695-702.

[41] Zhixin W, Lianhong Y, Wei H, et al. The value of the use of plasma B-type natriuretic peptide among acute ischemic stroke patients in a Chinese emergency department. Clinical Neurology and Neurosurgery 2013;115(9):1671-6.

[42] Montaner J, Perea-Gainza M, Delgado P, et al. Palacios. Etiologic diagnosis of ischemic stroke subtypes with plasma biomarkers. Stroke 2008;39(8):2280-7.

[43] Renjen PN, Beg MA, Ahmad K. Epidemiological study of incidence and risk factors of Ischemic stroke subtypes according to Trial of ORG 10172 in acute stroke treatment criteria: a 3 years, hospital-based study. International J Med Pub Health 2015;5(1)50-4.

[44] Llombart V, Antolin-Fontes A, Bustamante A, et al. BType natriuretic peptides help in cardioembolic stroke diagnosis: pooled data meta-analysis. Stroke 2015;46(5):1187-95.

[45] Yukiiri K, Hosomi N, Naya T, et al. Plasma BNP as a surrogate marker for Cardioembolic stroke. BMC Neurology 2008;8:45-50.

[46] Eguchi K, Kario K, Shimada K, et al. Circadian variation of blood pressure and neurohumoral factors during the acute phase of stroke. Clin Exp Hypertens 2002;24(1-2):109-14.

[47] Etgen T, Baum H, Sander K, et al. Cardiac troponins and $\mathrm{N}$-terminal pro-brain natriuretic peptide in acute ischemic stroke do not relate to clinical prognosis. Stroke 2005;36(2):270-75.

[48] Cojocaru IM, Cojocaru M, Sapira V, et al. Could proBNP, uric acid, bilirubin, albumin and transferrin be used in making the distinction between stroke subtypes? Romanian J of Internal Medicine 2013;51(34):188-95.

[49] Tamura H, Watanabe T, Nishiyama S, et al. Elevated plasma brain natriuretic peptide levels predict left atrial appendage dysfunction in patients with acute ischemic stroke. Journal of Cardiology 2012;60(2):126-32. 
[50] Cakir Z, Saritas A, Emet M, et al. A prospective study of brain natriuretic peptide levels in three subgroups: Stroke with hypertension, stroke without hypertension, and hypertension alone. Ann Indian Acad Neurol 2010;13(1):47-51.

[51] Chen X, Zhan X, Chen M, et al. The prognostic value of combined NT-pro-BNP levels and NIHSS scores in patients with acute ischemic stroke. Intern Med 2012;51(20):2887-92.
[52] Saritas A, Cakir Z, Emet M, et al. Factors affecting the B-Type natriuretic peptide levels in stroke patients. Ann Acad Med Singapore 2010;39(5):385-9.

[53] Kim SH, Lee JY, Park SH, et al. Plasma B-type natriuretic peptide level in patients with acute cerebral infarction according to infarction subtype and infarction volume. Int J Med Sci 2013;10(1):103-9. 